\title{
Comparative study of induced and spontaneous labour in nulliparous women using modified WHO partograph
}

\author{
Kamlesh Yadav, Monika Ranga*, Ankur Nama
}

Department of Obstetrics and Gynecology, S. P. Medical College and Associated Group of Hospitals, Bikaner, Rajasthan, India

Received: 24 February 2020

Accepted: 27 March 2020

*Correspondence:

Dr. Monika Ranga,

E-mail: rangamonika.mr@gmail.com

Copyright: (C) the author(s), publisher and licensee Medip Academy. This is an open-access article distributed under the terms of the Creative Commons Attribution Non-Commercial License, which permits unrestricted non-commercial use, distribution, and reproduction in any medium, provided the original work is properly cited.

\begin{abstract}
Background: Induced or spontaneous labour has implication on the eventual mode of delivery and neonatal outcome. The aim of study is to compare mean duration of labour andmaterno-foetal outcome of induced versus spontaneous labour among nulliparous women using modified WHO partograph.

Methods: The study was conducted in nulliparous women coming at term in active phase of labour (with cervical dilatation at least $4 \mathrm{~cm}$ ) either spontaneous or induced, both labouring women were monitored using modified WHO partograph. Outcomes measures include requirement of augmentation of labour with oxytocin, mean duration of labour, eventual mode of delivery and the materno foetal outcome.

Results: A total 100 women were compared in each group. There was no difference in mean age group, BMI, gestational age. More women had spontaneous vaginal delivery among those with spontaneous labour (76\% versus $58 \%)(\mathrm{p}=0.033)$. The mean duration of second stage of labour was significantly more in induced labour (16.25 minutes) than in spontaneous labour (14.60 minutes) $(\mathrm{p}=0.0212)$. The mean Apgar scores were comparable in two groups. Induced labour is comparable to spontaneous labour regarding fetomaternal outcomes but with increased rate of caesarean deliveries.

Conclusions: Study concluded from our study that in spontaneous group mean duration of labour was less than induced group and most of the patient delivered vaginally. In induced group rate of caesarean was higher and requirement of oxytocin for labour augmentation was also more than spontaneous group. Maternal complications were also found more in induced group than spontaneous group whereas neonatal outcome was similar in both the groups. We observed in our study that induced labour can be a safe procedure among nulliparous women if labour is partographically monitored by WHO modified partograph.
\end{abstract}

Keywords: Induced labour, Nulliparous women, Spontaneouslabour, World health organization partograph

\section{INTRODUCTION}

Labour is a natural physiological process characterized by progressive increase in frequency, intensity and duration of uterine contractions resulting in effacement and dilatation of the cervix with descent of the fetus through the birth canal. Labour induction is one of the most common obstetrical procedure, involving nearly $20 \%$ of all deliveries; and the rate continues to rise. ${ }^{1}$ In the US, the rate of labour induction has increased steadily from $9.5 \%$ in 1990 to $22.8 \%$ in $2007 .^{2}$ Induction of labour is the artificial initiation of uterine contraction prior to their spontaneous onset, leading to progressive dilatation and effacement of the cervix and delivery of the baby. ${ }^{3,4}$ Induction of labour is indicated when benefits (maternal or fetal) of elective early delivery outweigh potential risks imposed by continuing the pregnancy, typically in instances of post-term pregnancy, premature rupture of 
membranes (PROM), oligohydramnios, fetal growth restriction, hypertension, diabetes mellitus, and other maternal or fetal diseases. ${ }^{5}$ There are certain risks associated with induction of labour like prolonged labour, caesarean delivery, postpartum haemorrhage, fetal heart rate abnormalities, chorioamnionitis and possible birth trauma.

According to most authorities, the best way to monitor labour is with the help of a partograph. Partogram is a composite graphical record of key data (maternal and fetal) during labour entered against time on a single sheet of paper. Relevant measurements include statistics such as cervical dilatation, fetal heart rate, duration of labour and vital signs. An accurate record of the progress in labour can be obtained by it. Any delay or deviation from normal may be detected quickly and treated accordingly. ${ }^{6}$

The first WHO partograph or 'composite partograph', covers a latent phase of labour of up to 8 hours and an active phase beginning when the cervical dilatation reaches $3 \mathrm{~cm}$. The active phase is provided with an alert line and an action line, drawn 4 hours apart on the partograph as aids to monitoring labour. This partograph is based on the principle that during active labour, the rate of cervical dilation should not be slower than 1 $\mathrm{cm} /$ hour. A lag time of 4 hours between slowing of labour and the need for intervention is unlikely to compromise the foetus or the mother and avoids unnecessary intervention. Vaginal examination should be performed as infrequently as is compatible with safe practice (4 hours is recommended). Moreover, differentiating the latent phase from false labour being difficult, diagnosis is often made in retrospect. ${ }^{7}$ To alleviate these disadvantages, a WHO 'modified partograph' was introduced by removing the latent phase and considering the beginning of active phase at $4 \mathrm{~cm}$ dilatation of cervix instead of $3 \mathrm{~cm}$.

This study was conducted to compare the mean duration of labour and maternofoetal outcome in nulliparous women by using modified WHO partograph.

\section{METHODS}

After receiving approval from departmental research committee, the present study was conducted in the department of obstetrics and gynaecology, S. P. Medical College and Associated Group of Hospitals, Bikaner, Rajasthan which was prospective randomized clinical trial conducted from 1 October 2018 to 30 September 2019.

A total 200 women was enrolled in the study after fulfilling the inclusion and exclusion criteria. Proper counseling was done and written informed consent was taken. In which we recruited women whose Labour was either electively induced or spontaneous at $38+0$ to $41+6$ weeks of gestation.
The study was conducted in pregnant nulliparous women coming at term in active phase of labour (with cervical dilatation at least $4 \mathrm{~cm}$ ) either spontaneous or induced. The study population was divided into two equal groups:

- $\quad$ Spontaneous onset of labour, who reached $\geq 4 \mathrm{~cm}$ dilatation

- Labour induced with inducing agents like PGE1 (misoprostol), PGE2 (dinoprostone gel), oxytocin and who reached $\geq 4 \mathrm{~cm}$ dilatation.

\section{Inclusion criteria}

- $\quad$ Singleton pregnancy

- Gestational age >38 week- 41 weeks.

- Live foetus

- Vertex presentation

- PROM

- Nulliparous

- Consenting patients.

\section{Exclusion criteria}

- Multiple pregnancies

- Elective CS

- Antepartum haemorrhage

- Congenital malformation

- Abnormal presentation

- Multigravida

- Previous caesarean section

- In utero fetal death

- Non-obstetrical medical diseases.

- Non consenting patients

- Gestational age <38 weeks and >41 weeks

- Hypertensive disorders of pregnancy.

Gestational age was estimated by the date recorded as the first day of the last menstrual period or using prenatal ultrasound measurements.

Patient who had spontaneous onset of labour and reached $\geq 4 \mathrm{~cm}$ of cervical dilation was included in Group A and patient who were induced and reached $\geq 4 \mathrm{~cm}$ were included in Group B, and progress of labour was monitored by modified WHO partograph.

Fetal heart rate was recorded half hourly. The state of membrane "I" if membranes are intact, "C" if membranes were ruptured and liquor clear, "M" if membranes were ruptured and liquor meconium stained. Moulding of head at initial examination and subsequent vaginal examination was noted and scoring was done as + or ++ .

The most important measures of progress in labour, the rate of dilatation of the cervix and the rate of descent of the fetal presenting part, were recorded by plotting the cervical dilation on the vertical line on the left-hand side of the graph in centimetres from 4 to $10 \mathrm{~cm}$ (Figure 1). 


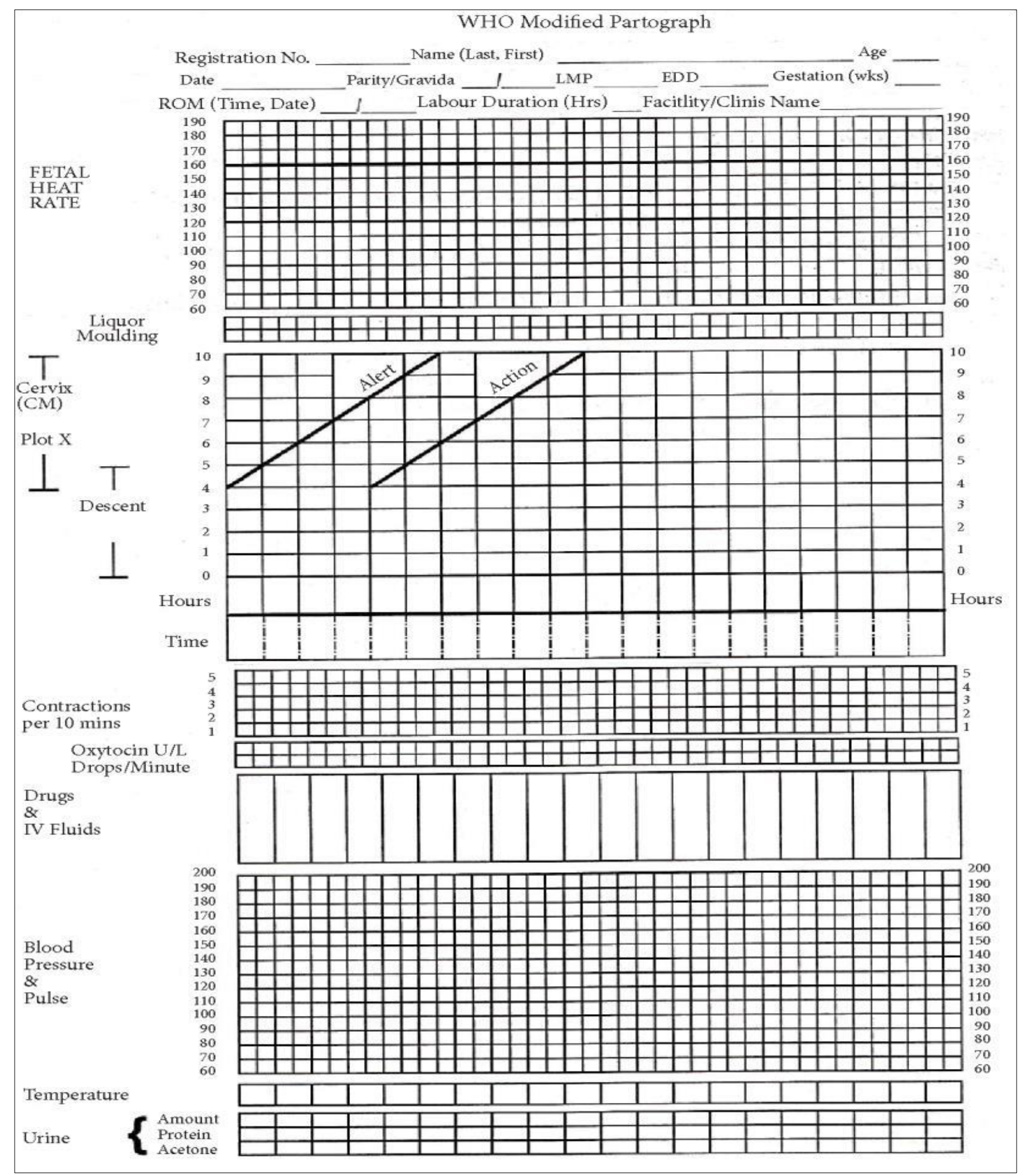

Figure 1: WHO modified partograph.

\section{Statistical analysis}

The quantitative data, comparison was performed using chi-square test with/without Yates's correction, student's ' $t$ ' test and analysis of variance. Group averages were reported as mean \pm standard deviation.

\section{RESULTS}

The demographic characteristics shows no significant difference among both group in mean age, weight, height, BMI, gestational age (Table 1). 
Table 1: General characteristics of study participants in both groups.

\begin{tabular}{|llll|}
\hline Variables & GroupA & GroupB & $\begin{array}{l}\text { p } \\
\text { value }\end{array}$ \\
\hline Age (years) & $25.16 \pm 7.13$ & $24.87 \pm 6.94$ & 0.310 \\
\hline Weight (kgs) & $61.28 \pm 9.53$ & $60.66 \pm 9.11$ & 0.539 \\
\hline Height (cms) & $158.54 \pm 18.47$ & $157.76 \pm 19.06$ & 0.446 \\
\hline $\begin{array}{l}\text { Body mass } \\
\text { index }\end{array}$ & $23.57 \pm 4.48$ & $23.32 \pm 3.68$ & 0.394 \\
\hline $\begin{array}{l}\text { Gestational age } \\
\text { (weeks) }\end{array}$ & $39.02 \pm 1.13$ & $39.33 \pm 0.98$ & 0.079 \\
\hline
\end{tabular}

Requirement of augmentation of labor with oxytocin were $42 \%$ of Group A while $78 \%$ in Group B. The difference was statistically highly significant $(\mathrm{p}<0.05)$ (Table 2).

Table 2: Distribution of cases table in both the groups according to their requirement of augmentation of labor with oxytocin.

\begin{tabular}{|llll|}
\hline Augmentation & $\begin{array}{l}\text { Group A } \\
\left(\mathbf{N}_{\mathbf{A}}=\mathbf{1 0 0}\right)\end{array}$ & $\begin{array}{l}\text { Group B } \\
\left(\mathbf{N}_{\mathbf{B}}=\mathbf{1 0 0}\right)\end{array}$ & $\begin{array}{l}\mathbf{p} \\
\text { value }\end{array}$ \\
\cline { 1 - 3 } Yes & $42(42 \%)$ & $78(78 \%)$ & \multirow{2}{*}{0.001} \\
\hline No & $58(58 \%)$ & $22(22 \%)$ & \\
\hline
\end{tabular}

Mean active phase of Group A was 3.48 hours and in Group B was 3.54 hours i.e. statistically insignificant. The second stage was of more duration in Group B i.e. $16.25 \mathrm{~min}$ as compared to Group A i.e. $14.25 \mathrm{~min}$. The difference in duration of second stage in both groups was observed to be statistically significant (Table 3 ).

Table 3: Distribution of cases of both the groups according to active phase and second stage of labour $(\mathrm{NA}=\mathrm{NB}=\mathbf{1 0 0})$.

\begin{tabular}{|llllll|}
\hline Sr. No. & Group & N & Mean & SD & $\begin{array}{l}\text { p } \\
\text { value }\end{array}$ \\
\hline \begin{tabular}{llllll|} 
Active phase \\
(hours)
\end{tabular} & A & 100 & 3.48 & 1.34 & \multirow{2}{*}{0.497} \\
\cline { 2 - 6 } & $\mathrm{B}$ & 100 & 3.54 & 1.65 & \\
\hline $\begin{array}{l}\text { Second stage } \\
\text { (minutes) }\end{array}$ & $\mathrm{A}$ & 80 & 14.60 & 3.89 & \multirow{2}{*}{0.0212} \\
\cline { 2 - 6 } & $\mathrm{B}$ & 60 & 16.25 & 6.60 & \\
\hline
\end{tabular}

Table 4: Distribution of cases in both the groups according to mode of delivery.

\begin{tabular}{|llll|}
\hline Mode of delivery & $\begin{array}{c}\text { Group A } \\
\left(\mathbf{N}_{\mathbf{A}}=\mathbf{1 0 0}\right)\end{array}$ & $\begin{array}{l}\text { Group B } \\
\left(\mathbf{N}_{\mathbf{B}}=100\right)\end{array}$ & $\begin{array}{l}\text { p } \\
\text { value }\end{array}$ \\
\hline Vaginal delivery & $76(76 \%)$ & $58(58 \%)$ & 0.033 \\
\hline Caesarean section & $24(24 \%)$ & $42(42 \%)$ & 0.010 \\
\hline
\end{tabular}

A total $76 \%$ cases were delivered through vaginal delivery in Group A whereas 58\% cases in Group B. Caesarean section was $24 \%$ and $42 \%$ in Group A and Group B respectively. The occurrence of vaginal delivery and caesarean section was observed to be statistically significant $(\mathrm{p}<0.05)$ (Table 4).
Table 5: Distribution of both groups according to maternal complications.

\begin{tabular}{|lll|}
\hline $\begin{array}{l}\text { Maternal } \\
\text { complications }\end{array}$ & $\begin{array}{l}\text { Group A } \\
\left(\mathbf{N}_{\mathbf{A}}=\mathbf{1 0 0}\right)\end{array}$ & $\begin{array}{l}\text { Group B } \\
\left(\mathbf{N}_{\mathbf{B}}=\mathbf{1 0 0}\right)\end{array}$ \\
\hline Uterine tachysystole & $0(0 \%)$ & $2(2 \%)$ \\
\hline $1^{\mathrm{o}}$ perinealtear & $2(2 \%)$ & $5(5 \%)$ \\
\hline Atonic PPH & $5(5 \%)$ & $5(5 \%)$ \\
\hline Cervical tear & $1(1 \%)$ & $4(4 \%)$ \\
\hline
\end{tabular}

Table 6: Distribution of cases of both the groups according to Apgar score.

\begin{tabular}{|c|c|c|c|c|}
\hline \multirow[t]{2}{*}{ Groups } & \multicolumn{2}{|c|}{$\begin{array}{l}\text { Apgar score at } 1 \\
\text { minute }\end{array}$} & \multicolumn{2}{|c|}{$\begin{array}{l}\text { Apgar score at } 5 \\
\text { minutes }\end{array}$} \\
\hline & Mean & SD & Mean & SD \\
\hline A & 7.58 & 1.09 & 8.09 & 1.13 \\
\hline B & 7.86 & 1.05 & 8.33 & 1.10 \\
\hline $\mathrm{p}$ value & 0.066 & & 0.130 & \\
\hline
\end{tabular}

In Group A, 5\% suffered from atonic PPH, 2\% cases had $1^{\circ}$ perineal tear and $1 \%$ had cervical tear whereas in group B $2 \%$ had uterine tachysystole, $5 \%$ had $1^{\circ}$ perineal tear and atonic PPH and $4 \%$ had cervical tear. It shows that occurrence of maternal complications were higher in Group B as compared to Group A (Table 5).

Mean Apgar score at 1 minute in Group A was 7.58 while in Group B was 7.86. Mean Apgar score at 5 minutes was 8.09 in Group A and 8.33 in Group B. The difference in Apgar scores at 1 minute and 5 minutes in both groups was observed to be statistically insignificant $(\mathrm{p}>0.05)$ (Table 6).

\section{DISCUSSION}

Present study is a prospective hospital based randomized clinical trial conducted on nulliparous pregnant women of 38-41 weeks gestation for 1-year duration. Two hundred pregnant women were selected at random and were divided into two equal groups-Group A included the patients who had spontaneous onset of labour and reached $\geq 4 \mathrm{~cm}$ of cervical dilation and Group B included the patients who were induced and reached $\geq 4 \mathrm{~cm}$ of cervical dilatation. Progress of labour was monitored by modified WHO partograph and maternal and fetal outcome were compared. The study had following observations as discussed with available literature.

Among $42 \%$ of patients in spontaneous group required augmentation of labour with oxytocin whereas this proportion was significantly higher i.e. $78 \%$ in induced group. The results are concurrent with the study conducted by Yadav P et al observed $36.7 \%$ in Group A and $66.7 \%$ in Group B required augmentation. ${ }^{8}$ Thus we conclude that augmentation is frequently required in induced patients, so proper monitoring of labour and dose titration according to uterine contraction is critical in this group. 
In this study mean duration of active phase in Group A was 3.48 hours and in Group B was 3.54 hours i.e. statistically insignificant. This is similar to the study of Gupta $\mathrm{S}$ et al in which the mean duration of active labour was 3.42 \pm 1.44 hours in Group A and 3.58 \pm 1.71 hours in Group B $(\mathrm{p}=0.436) .{ }^{10}$ The second stage was longer in Group B i.e. $16.25 \mathrm{~min}$. as compared to $14.25 \mathrm{~min}$ in Group A. The difference in duration of second stage in both groups was observed to be statistically significant ( $p$ $<0.05$ ). Gupta $S$ et al found that the mean duration of second stage of labour was significantly more in induced labour group (16.34 minutes) than in spontaneous labour group (14.72 minutes) $(\mathrm{p}=0.0212) .{ }^{9}$ Similarly Kumari G et al, also found that second stage of labour was significantly longer in induced group compared to spontaneous group. ${ }^{10}$

Caesarean section rate was $42 \%$ in Group B where as in Group A it was $24 \%$. Thus, the mode of delivery among the groups was observed to be statistically significant ( $p$ $<0.05)$. Patients with spontaneous onset of labour had higher chances of vaginal deliveries. These observations are similar to Orji and Olabode et al study in which larger number of women had spontaneous vaginal delivery among those in spontaneous labour group $(72.1 \%$ versus $64.7 \%) \mathrm{p}=0.0001 .^{11}$ There were less caesarean section among those in spontaneous labour $(20.6 \%$ versus $35.3 \%$ ). Gupta $\mathrm{S}$ et al also found more women had spontaneous vaginal delivery among those with spontaneous labour (88.96\% versus $80 \%)$ ( $p=0.0396){ }^{9}$ Sujata $\mathrm{P}$ et al, found the rate of primary cesarean section in induced group was $56 \%$ whereas $21 \%$ in spontaneous labour group. ${ }^{32}$ Anamikasingh et al, found more women had spontaneous vaginal delivery among those in spontaneous labour $(72.1 \%$ versus $64.7 \%) \mathrm{p}=0.0001 .^{12}$

Most common complication was atonic PPH in both the groups, few cases had $1^{\circ}$ perineal tear and cervical tear. Uterine tachysystole found only in Group B. The occurrence of maternal complications were higher in Group B. Similar results were observed in the study by Gupta S et al. ${ }^{9}$

Higher Apgar score was observed in Group B. The mean Apgar scores at 1 minute and 5 minutes in both groups was observed to be statistically insignificant. $(p>0.05)$ Gupta S et al and Ojaswini Patel et al also observed that the mean Apgar scores were comparable in two groups. ${ }^{9,13}$

\section{CONCLUSION}

Study concluded that in spontaneous group mean duration of labour was less than induced group and most of the patient delivered vaginally. In induced group rate of caesarean was higher and requirement of oxytocin for labour augmentation was also more than spontaneous group. Maternal complications were also found more in induced group than spontaneous group whereas neonatal outcome was similar in both the groups. This study observed that induced labour can be a safe procedure among nulliparous women if labour is partographically monitored by WHO modified partograph.

Funding: No funding sources

Conflict of interest: None declared

Ethical approval: The study was approved by the Institutional Ethics Committee

\section{REFERENCES}

1. Vrouenraets FP, Roumen FJ, Dehing CJ, van den Akker ES, Aarts MJ, Scheve EJ. Bishop score and risk of cesarean delivery after induction of Labour in nulliparous women. Obstet Gynecol. 2005;105:6907.

2. Caughey AB, Sundaram V, Kaimal AJ, Gienger A, Cheng YW, McDonald KM, et al. Systematic review: elective induction of Labour versus expectant management of pregnancy. Ann Intern Med. 2009;151:252-63.

3. Brennand J, Greer I. Induction of labour: New Horizons. Hospital Med. 1998;59:856-60.

4. Heffner LJ, Elkin E, Fretts RC. Impact of labour induction, gestational age, and maternal age on cesarean delivery rates. Royal College of Obstetricians and Gynaecologists. Induction of labour. London RCOG Press 1998, Guidance No 16. Obstet Gynecol. 2003;102:287-93.

5. Mitchell MD, Flint APF, Bibby J, Arnol JM, Anderson ABM, Turnbull C. Rapid increase in plasma PG concentration after vaginal examination amniotomy. Brit Med J. 1997;2:1183-8.

6. mathai $\mathrm{m}$. the partograph for the prevention of obstructed labour. Clin Obstet Gynecol. 2009;52(2):256-69.

7. Mathews JE, Rajaratnam A, George A, Mathai M. Comparison of two World Health Organization (WHO) partographs. Int J Gynecol. 2007;96(2):14750.

8. Yadav P, Verma M, Harne S, Sharma M. Comparison of spontaneous labour with induced labour in nulliparous women using modified WHO partograph. Int J Reprod Contracept Obstet Gynecol. 2016;5:4005-8.

9. Gupta S, Shekhawat U, Mital P, Meena M. To study the fetomaternal outcome and progress of labour among induced versus spontaneous labour in nulliparous women (using modified WHO partograph). Sch J App Med Sci. 2014;2(5A):15778.

10. Kumari G, Poonia K, Rani D. Prospective study to assess the fetal and maternal outcome in cases of low risk primigravida in induced versus spontaneous onset of labour. Inter J Clin Obstet Gynaecol. 2018;2(3):68-72.

11. Orji E O and Olabode TO. Comparative study of labour progress and delivery outcome among induced versus spontaneous labour in nulliparous 
women using modified WHO partograph. NJOG. 2008;3(1):24-8.

12. Singh A, Rao SB, Sherigar B, D'souza R, Soumya R, Kaveri V. Comparison of progress of labour and maternofetal outcome among induced versus spontaneous labour in nulliparous women using modified WHO partograph. Int J Reprod Contracept Obstet Gynecol. 2018;7:415-8.

13. Patel, Ojaswini, et al. Comparative study of labour progress and delivery outcome among induced versus spontaneous labour in nulliparous women using modified who partograph. J Evolut Med Dent Sci. 2017;6(23):1844.

Cite this article as: Yadav K, Ranga M, Nama A. Comparative study of induced and spontaneous labour in nulliparous women using modified WHO partograph. Int J Reprod Contracept Obstet Gynecol 2020;9:2014-9. 